\title{
Potential genes and pathways associated with heterotopic ossification derived from analyses of gene expression profiles
}

\author{
Zhanyu Yang ${ }^{1,2}$, Delong Liư ${ }^{1,2}$, Rui Guan', Xin Li', Yiwei Wang ${ }^{1}$ and Bin Sheng ${ }^{1,2^{*}}$
}

\begin{abstract}
Background: Heterotopic ossification $(\mathrm{HO})$ represents pathological lesions that refer to the development of heterotopic bone in extraskeletal tissues around joints. This study investigates the genetic characteristics of bone marrow mesenchymal stem cells (BMSCs) from HO tissues and explores the potential pathways involved in this ailment.
\end{abstract}

Methods: Gene expression profiles (GSE94683) were obtained from the Gene Expression Omnibus (GEO), including 9 normal specimens and $7 \mathrm{HO}$ specimens, and differentially expressed genes (DEGs) were identified. Then, proteinprotein interaction (PPI) networks and Gene Ontology (GO) and Kyoto Encyclopedia of Genes and Genomes (KEGG) enrichment analyses were performed for further analysis.

Results: In total, 275 DEGs were differentially expressed, of which 153 were upregulated and 122 were downregulated. In the biological process (BP) category, the majority of DEGs, including EFNB3, UNC5C, TMEFF2, PTH2, KIT, FGF13, and WISP3, were intensively enriched in aspects of cell signal transmission, including axon guidance, negative regulation of cell migration, peptidyl-tyrosine phosphorylation, and cell-cell signaling. Moreover, KEGG analysis indicated that the majority of DEGs, including EFNB3, UNC5C, FGF13, MAPK10, DDIT3, KIT, COL4A4, and DKK2, were primarily involved in the mitogen-activated protein kinase (MAPK) signaling pathway, Ras signaling pathway, phosphatidylinositol-3-kinase/protein kinase B (PI3K/Akt) signaling pathway, and Wnt signaling pathway. Ten hub genes were identified, including CX3CL1, CXCL1, ADAMTS3, ADAMTS16, ADAMTSL2, ADAMTSL3, ADAMTSL5, PENK, GPR18, and CALB2.

Conclusions: This study presented novel insight into the pathogenesis of $\mathrm{HO}$. Ten hub genes and most of the DEGs intensively involved in enrichment analyses may be new candidate targets for the prevention and treatment of $\mathrm{HO}$ in the future.

Keywords: Heterotopic ossification, Bioinformatic analysis, Differentially expressed genes, Protein-protein interaction, Functional enrichment analysis

\footnotetext{
*Correspondence: shengbin2009@163.com

'Department of Orthopaedics and Traumatology, Hunan Provincial People's

Hospital, the First Affiliated Hospital of Hunan Normal University, No. 61

Jiefang West Road, Changsha, Hunan 410000, People's Republic of China

${ }^{2}$ Hunan Emergency Center, No. 90 Pingchuan Road, Changsha, Hunan

410000, People's Republic of China
}

C C The Author(s). 2021 Open Access This article is licensed under a Creative Commons Attribution 4.0 International License, which permits use, sharing, adaptation, distribution and reproduction in any medium or format, as long as you give appropriate credit to the original author(s) and the source, provide a link to the Creative Commons licence, and indicate if changes were made. The images or other third party material in this article are included in the article's Creative Commons licence, unless indicated otherwise in a credit line to the material. If material is not included in the article's Creative Commons licence and your intended use is not permitted by statutory regulation or exceeds the permitted use, you will need to obtain permission directly from the copyright holder. To view a copy of this licence, visit http://creativecommons.org/licenses/by/4.0/ The Creative Commons Public Domain Dedication waiver (http://creativecommons.org/publicdomain/zero/1.0/) applies to the data made available in this article, unless otherwise stated in a credit line to the data. 


\section{Background}

Heterotopic ossification (HO) represents pathological lesions, referred to as the development of heterotopic bone in extraskeletal tissues around joints, which often occurs in the elbow, thigh, pelvis, and shoulder [1,2]. The clinical manifestations were altered with the progression of the disease. Local pain, tenderness, swelling, and stiffness of the involved joints were present in the early stage of HO. At the end of the disease, patients even present with complete ankyloses, which seriously damages their quality of life [3]. The specific causes of $\mathrm{HO}$ were still uncertain. It is generally believed that the occurrence of $\mathrm{HO}$ is related to genetic susceptibility and severe trauma. Progressive ossifying fibrous dysplasia (FOP), a genetic hereditary form of $\mathrm{HO}$, is extremely rare, with a prevalence of approximately 1:2,000,000 in the population [4-7]. However, there was a much higher incidence of $\mathrm{HO}$ following softtissue trauma, amputations, and central nervous system injury, such as cerebral anoxia, encephalitis, traumatic brain injuries, and spinal cord lesions $[8,9]$.

At present, the only effective way to treat $\mathrm{HO}$ is surgical resection of ossified tissue. Since HO is prone to recurrence, this method is only temporarily effective [10]. Moreover, when the ossification tissue invades the large blood vessels and nerves, the complication rate caused by resection is also increased. Studies have shown that $\mathrm{HO}$ is a disease with unknown pathogenesis, inadequate prevention and treatment, and a high disability rate [11]. Therefore, to find a more effective therapeutic method, we need to better understand the pathogenesis of $\mathrm{HO}$ [12].

Recently, translational medicine has provided a new way of thinking that connects basic medical research with clinical treatment [13]. Bioinformatics based on genomic genetics and omics chips has a close interaction with systems medicine theory and automatic communication technology, which speeds up the industrialization process of the transformation from scientific research to clinical application. Its application in orthopedics will also lead to the rapid shortening of the distance between foundation and clinic and a new generation of orthopedic surgeons [14]. The bioinformatics analysis of gene expression, which serves as a key technology in mechanistic exploration, plays an important role in screening gene mutations and studying genetic behavior.

Our study screened out the genes differentially expressed in bone marrow mesenchymal stem cells (BMSCs) from $\mathrm{HO}$, which were identified from a public dataset. In this work, we sought to synthesize proteinprotein interaction (PPI) network analysis and Gene Ontology (GO) and Kyoto Encyclopedia of Genes and Genomes (KEGG) enrichment analysis among DEGs to explore the potential mechanism of $\mathrm{HO}$ and candidate gene targets, which may be used to prevent, alleviate and even reverse the progression of $\mathrm{HO}$.

\section{Methods}

\section{Microarray data resource}

A gene expression profile dataset (GSE94683), GSE94683 [15], a gene expression profile dataset obtained from a public genomics data repository (GEO database, http:// www.ncbi.nlm.nih.gov/geo/), was produced on the GPL10630 Agilent-021531 Whole Human Genome Oligo Microarray $4 \mathrm{x} 44 \mathrm{~K}$. According to the annotation information in the platform, the probes were alternated into corresponding gene symbols. GSE94683 contains 9 normal specimens and $7 \mathrm{HO}$ specimens. $\mathrm{HO}$ specimens were obtained from patients with injuries at Garches Hospital, Garches, France. Healthy specimens were obtained from patients after total hip surgery at Blois Hospital (Blois, France) and at Centre de Transfusion Sanguine des Armées (Percy Hospital, Clamart, France).

\section{Data processing and identification of DEGs}

Principal components analysis (PCA) and normalization were performed by ggbiplot and the preprocessCore package in R. After the preprocessing of the datasets, the identification of DEGs was processed using multiple linear regression models via the limma package of $R$ language. A probe without any corresponding gene symbol was eliminated, and a gene with many probes was averaged. All DEGs and the top 30 DEGs were demonstrated via a volcano plot, which was performed by the ggplot2 package. DEGs were screened by using classical $t$ test and $\mid \log 2$ (FoldChange) $\mid>2$ and adj. $P<0.05$ was defined as a threshold and criteria for the identification of statistically significant DEGs. The relative expression values of total DEGs and the top 30 upregulated and downregulated DEGs, which were extracted from the gene expression profile, were demonstrated by the hierarchical clustering heatmaps via the pheatmap package of $\mathrm{R}$ language.

\section{Functional enrichment analysis for DEGs}

KEGG is a data reservoir for unravelling advanced biological functions and pathways involved with genomic information [16]. GO is a tool for defining concepts or classifying gene biological functions by analyzing a large list of genes [17]. The Database for Annotation, Visualization and Integrated Discovery (DAVID), a webbased database resource that explores gene data, facilitates researchers to reveal potential genetic significance [18]. DAVID was used to perform the GO and KEGG enrichment analyses. The functional enrichment analyses were processed via the ggplot2 package in $\mathrm{R}$ and demonstrated by bubble plots.

\section{Integration of PPI network analysis}

The Search Tool for the Retrieval of Interacting Genes (STRING), an original online program that predicts the 
relationships and interactions among proteins involved [19], was applied to construct a functional network among proteins. Cytoscape, an open-access visual tool, was able to visualize processes and interactions among proteins. Molecular Complex Detection (MCODE), a plugin of Cytoscape, was used to explore intensive communications and discover the most significant module. "MCODE scores $\geq 5$ ", "k-score $=2$ ", "Max depth $=100$ ", "node score cut-off $=0.2$," and "degree cut-off $=2$ " were selected as criteria for the identification of significant modules.

\section{Hub genes selection and analyses}

CytoHubba, a plugin of Cytoscape applied with 12 topological analysis methods, was used to detect more comprehensive hub genes and avoid missing data. According to MCC, MNC, DMNC, and Degree, the top 25 genes were predicted. Venn diagrams were used to screen the hub genes by identifying the overlapping genes.

\section{Results}

\section{Data source and data preprocessing}

As large amounts of data were integrated into a gene expression profile (GSE94683), the original data were downloaded from the GEO database. PCA of datasets demonstrated that there were significant differences between HO samples and control samples (Fig. 1). Normalization of the data is presented in a boxplot (Fig. 2).
DEGs in $\mathrm{HO}$ samples compared with control samples

A total of 275 DEGs were identified on the basis of the criteria established, including 122 downregulated genes and 153 upregulated genes. The expression levels of the total and the top 30 DEGs are shown in volcano plots and heatmaps (Figs. 3 and 4), indicating that the expression level of DEGs could be used to effectively differentiate the two groups.

\section{Functional enrichment analysis for DEGs}

DAVID was used to perform functional enrichment analyses to explore the biological classification of DEGs and the top 10 items are shown in Fig. 5. In the biological process (BP) ontology, the majority of DEGs, including EFNB3, UNC5C, TMEFF2, PTH2, KIT, FGF13, and WISP3 were intensively enriched in cell signal transmission items, including axon guidance ( 9 genes), negative regulation of cell migration (7 genes), peptidyl-tyrosine phosphorylation (6 genes), and cell-cell signaling (10 genes). Moreover, KEGG analysis indicated that the majority of DEGs, including EFNB3, UNC5C, FGF13, MAPK10, DDIT3, KIT, COL4A4, and DKK2, were primarily involved in the axon guidance (7 genes), mitogen-activated protein kinase (MAPK) signaling pathway (9 genes), Ras signaling pathway (7 genes), phosphatidylinositol-3kinase/protein kinase B (PI3K/Akt) signaling pathway (9 genes), and Wnt signaling pathway (5 genes).

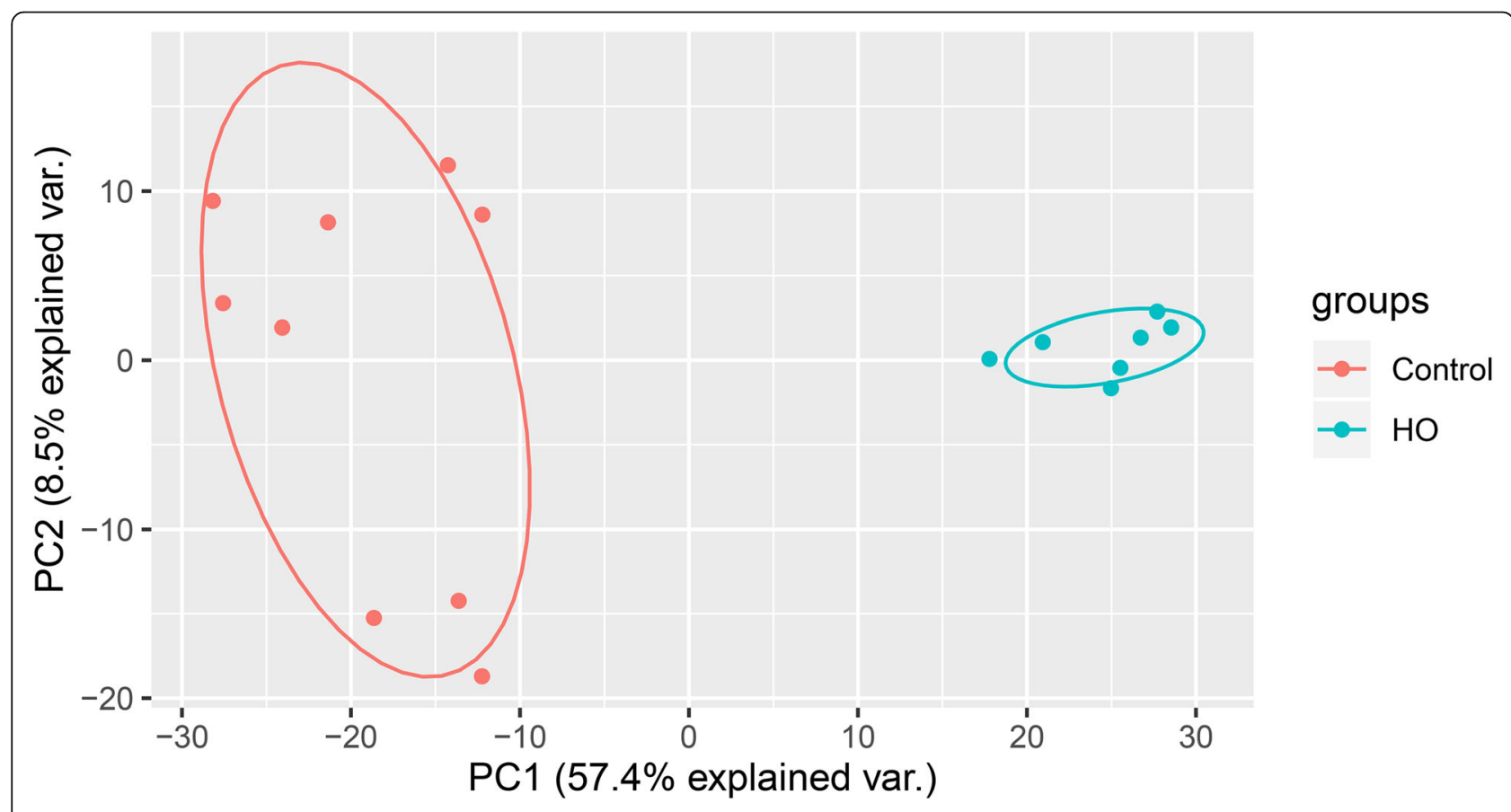

Fig. 1 Principal components analysis of datasets. Red represents samples from normal cohort. Blue represents samples from heterotopic ossification 


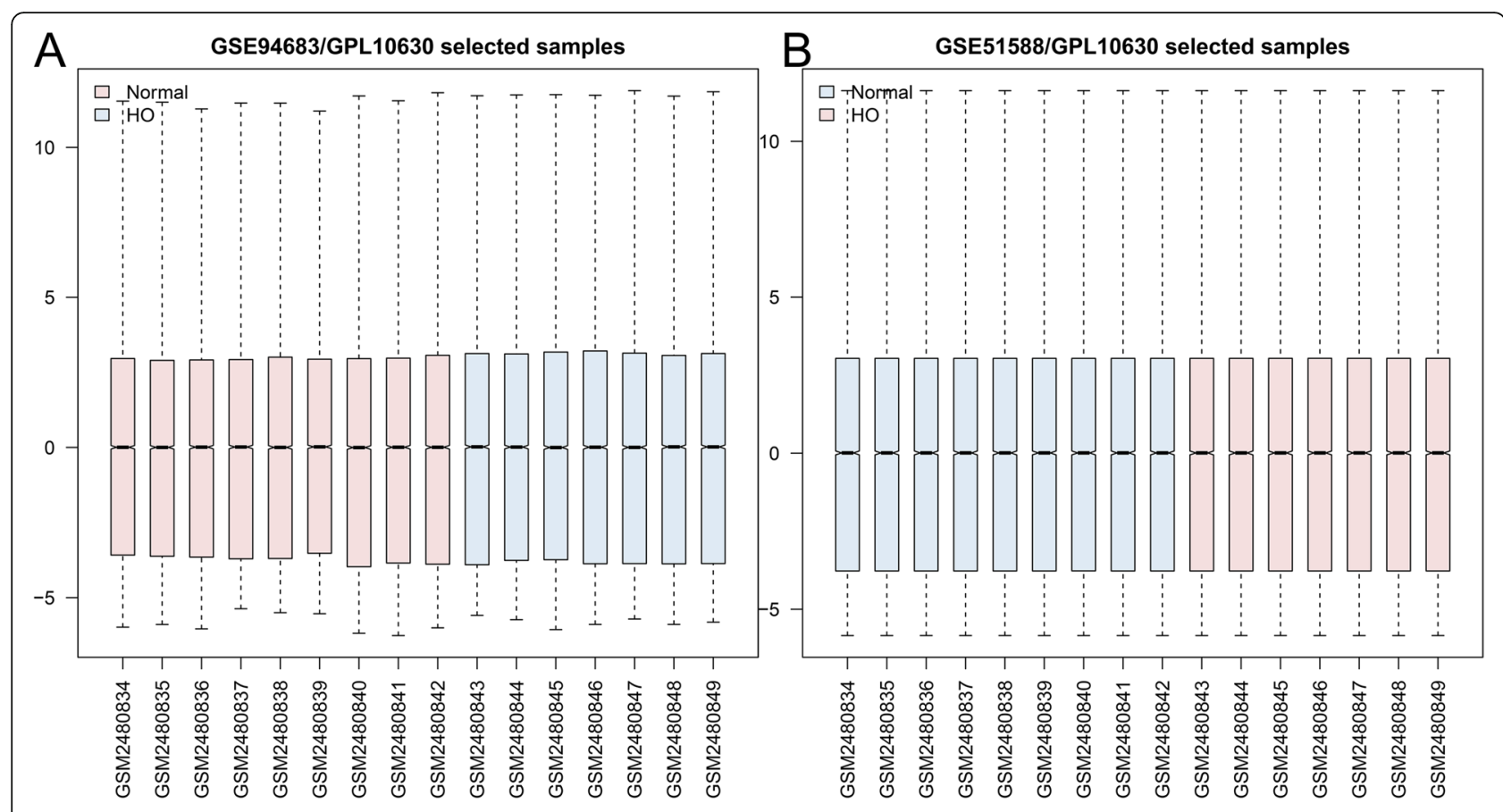

Fig. 2 Normalization of the sample data demonstrated by box plots. A Before processing and $\mathbf{B}$ after processing. HO = heterotopic ossification, DEGs = differentially expressed genes

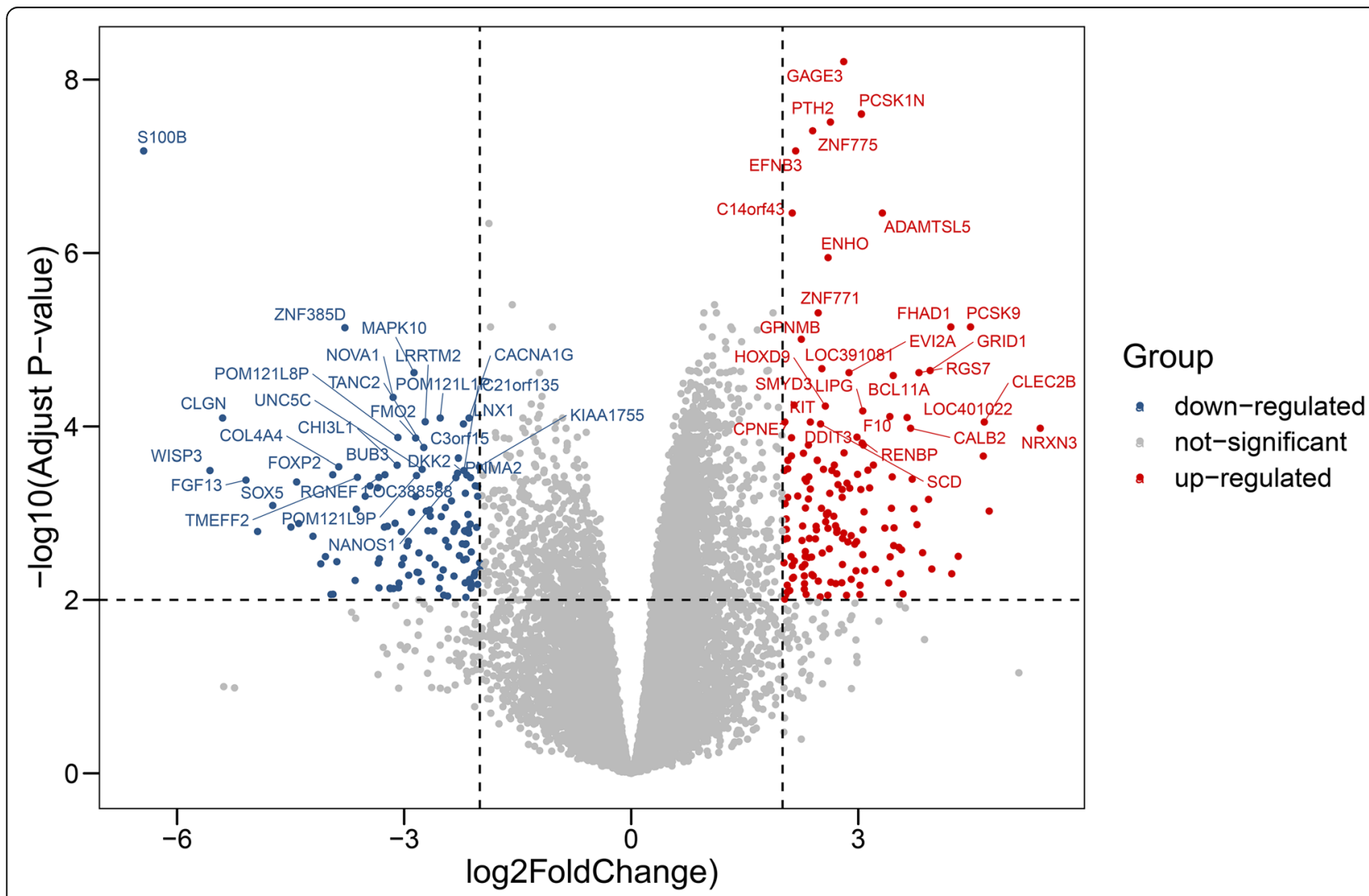

Fig. 3 DEGs screening identified by volcano plot. Grey refers to no difference in expression. Red refers to up-regulated expression. Blue refers to down-regulated expression 


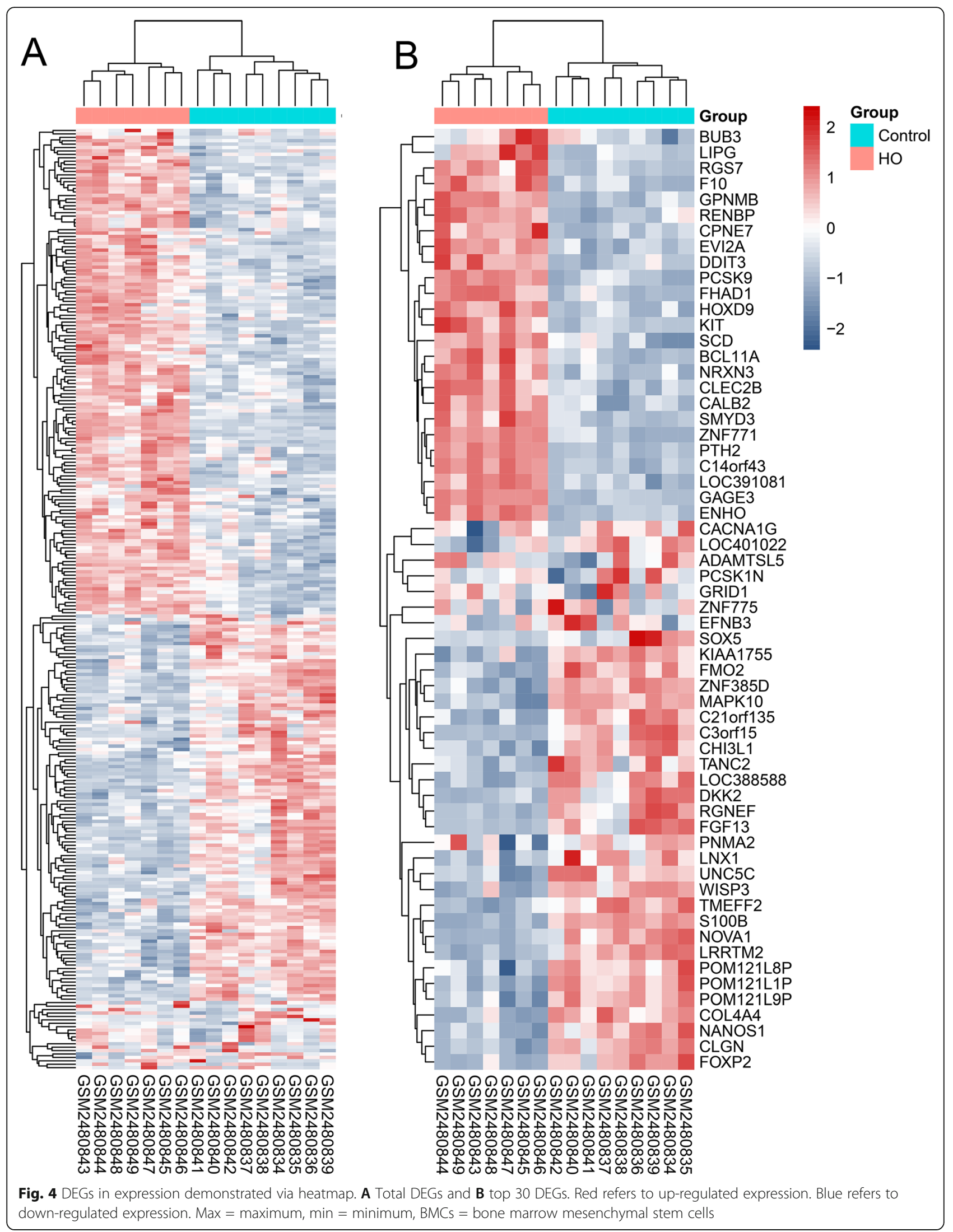




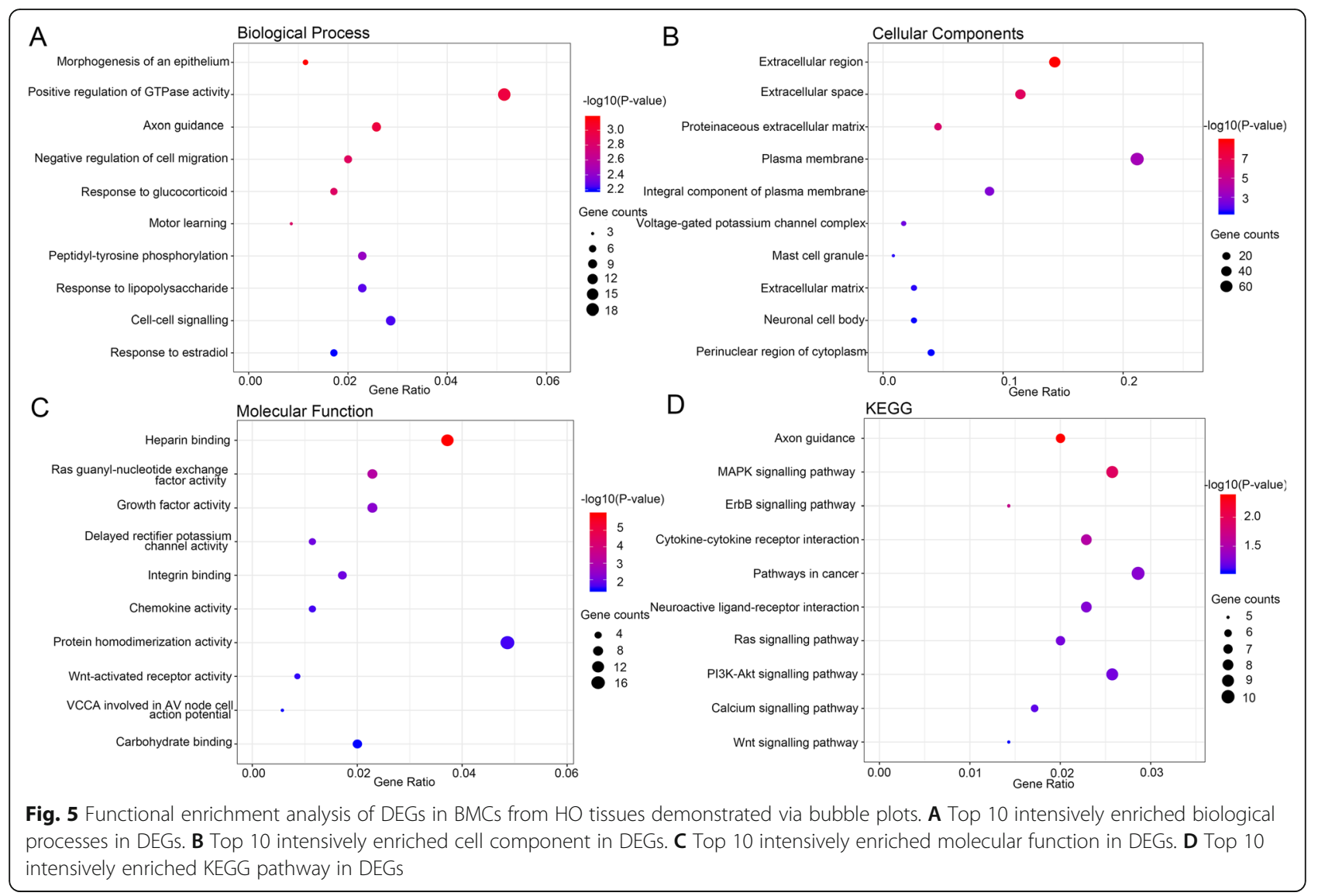

PPI network construction and hub gene selection

The PPI network was constructed after the functional relationship and interaction data obtained from STRING were imported into Cytoscape, and the top module was identified (Fig. 6). According to MCC, MNC, DMNC, and Degree, the top 25 genes $(10 \%)$ were predicted. Venn diagrams were used to select the hub genes, and CX3CL1, CXCL1,
ADAMTS3, ADAMTS16, ADAMTSL2, ADAMTSL3, ADAMTSL5, PENK, GPR18, and CALB2, were identified as the hub genes (Fig. 7).

\section{Discussion}

$\mathrm{HO}$ refers to a pathological process, involving a variety of etiologies, locations, mechanisms, and cell origins [3].

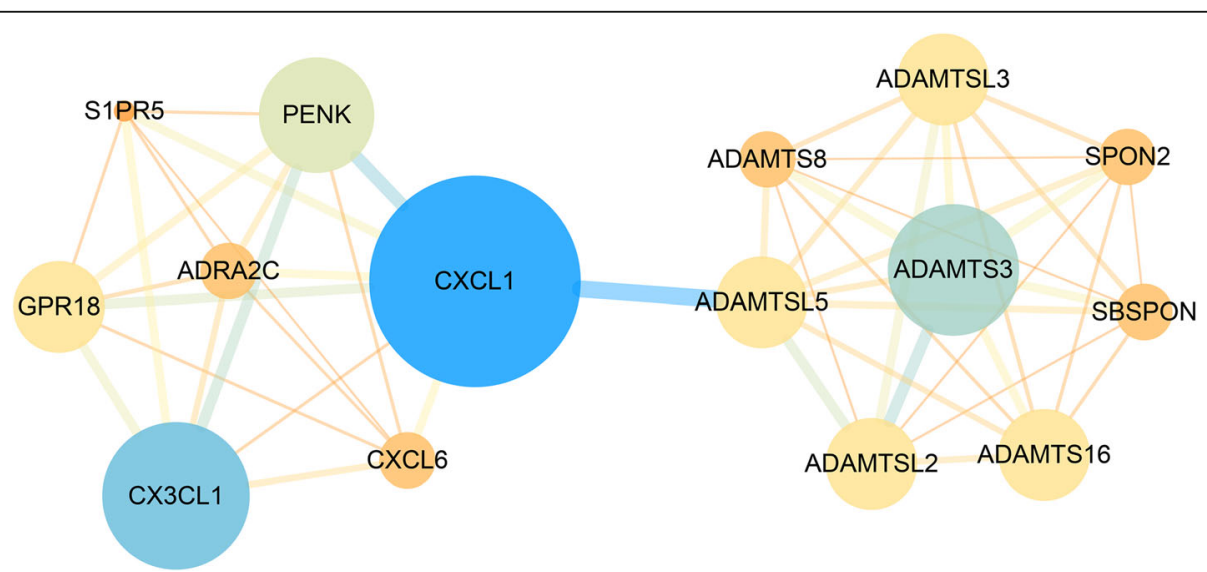

Fig. 6 The most significant module was identified with 15 nodes and 50 edges. Small-sized or brightly colored circles and lines indicate a lower value of the combined score 


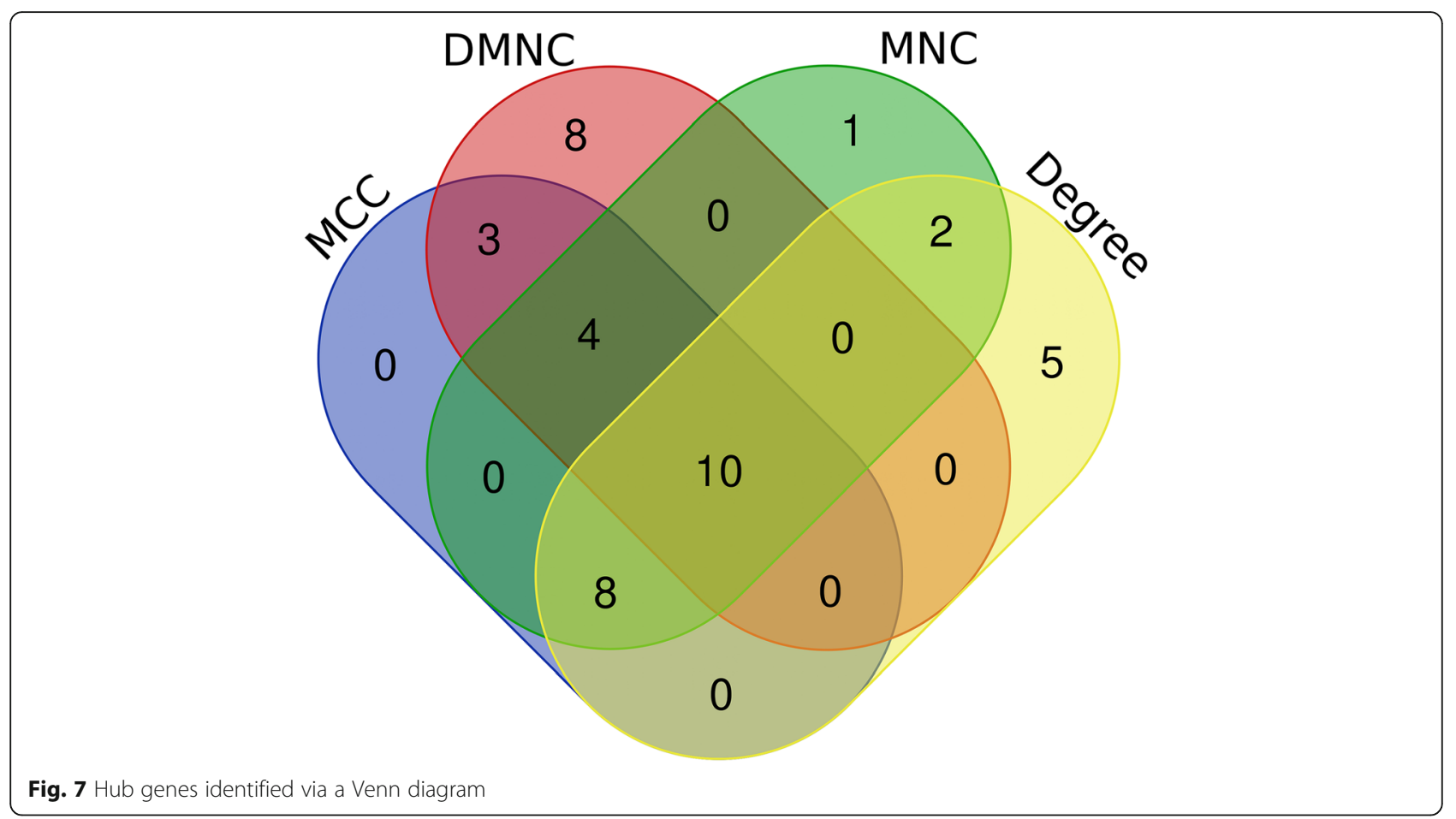

It has been reported that early diagnosis of $\mathrm{HO}$ is difficult due to a lack of evident signs and symptoms and limited treatment $[20,21]$. The way to manipulate inflammatory cascades to control HO formation is just beginning to be understood [3]. Therefore, it is urgent to explore the mechanisms of $\mathrm{HO}$ formation at the molecular level, to find novel, adequate, and effective treatment methods to alleviate, delay, or even reverse the development of HO.

Under the background of multiple pathological mechanisms, screening possible pathways and targets by means of translational medicine can effectively achieve the research purpose, reduce the research expenditure, and accelerate the time from basic research to clinical application. Whole-genome microarray and bioinformatic analysis facilitate the detection of genetic differences in the development of $\mathrm{HO}$, and provide a better way to explore the pathogenesis and identify novel candidates for early diagnosis and precise treatment. In the current study, 275 DEGs were identified, including 122 downregulated genes and 153 upregulated genes.

After that, functional enrichment analysis was performed, and the relationships and interactions among DEGs were predicted. The majority of DEGs, including KIT, FGF13, EFNB3, UNC5C, TMEFF2, WISP3, and PTH2 were intensively enriched in cell signal transmission items, including axon guidance, negative regulation of cell migration, peptidyl-tyrosine phosphorylation, and cell-cell signaling. Moreover, KEGG analysis indicated that the majority of DEGs, including KIT, DDIT3,
FGF13, EFNB3, UNC5C, MAPK10, and DKK2, were primarily involved in axon guidance, the MAPK signaling pathway, the Ras signaling pathway, the PI3K-Akt signaling pathway, and the Wnt signaling pathway. This is consistent with recent research findings that musclederived mesenchymal stem cells in soft tissue migrate to the area of trauma and inflammation, differentiate into osteoblasts and form heterotopic bone [22].

The PPI network of the DEGs has been constructed. The results indicate that CX3CL1, CXCL1, ADAMTS3, ADAMTS16, ADAMTSL2, ADAMTSL3, ADAMTSL5, PENK, GPR18, and CALB2 are hub genes.

Chemokines are able to mediate the migration and localization of immunocytes in the process of inflammation, which plays a vital role in manipulating the immune system. According to the conserved cysteine motifs, chemokines in humans are divided into four families (C, CC, CXC, and CX3C). Most chemokines are involved in the differentiation of osteoblasts and/or osteoclasts to varying degrees. CX3CL1, belonging to the CX3C subgroup, is a combination of chemotactic agents and adhesion molecules that has been shown to continuously control reshaping bone matrix by regulating bone remodeling at the cellular level [23, 24]. Current studies have reported that osteoblasts are able to express CX3CL1, and osteoclast progenitors are able to produce CX3C receptor 1 (CX3CR1) [25]. Cytokines originating from inflammation are able to significantly induce the expression of CX3CL1 in osteoblasts. Meanwhile, CX3CR1 was identified as a candidate for screening 
osteoclasts with inflammatory reactions [26-28]. It was reported that the interaction between membrane-bound CX3CL1 on osteoblasts and CX3CR1 expressed by osteoclast progenitors is able to promote the progress of terminal differentiation of osteoclast progenitors [25]. CX3CR1-deficient mice showed moderate but significantly increased trabecular bone mass, which was mainly due to the decrease in the number of osteoclasts [29]. In vitro experiments suggested that this phenotype can be explained by the decreased ratio of receptor activator of nuclear factor-kappa B ligand/osteoprotegerin (RANKL/ OPG), and the defect of spontaneous-formation of osteoclasts from CX3CR1-deficient bone marrow cells [29]. In general, these results indicate that CX3CL1 may be involved in osteoclast-mediated bone loss. CXCL1, belonging to the CXC subgroup, is a kind of growth factor that can send signals through CXC receptor 2 (CXCR2) [30]. CXCR2, a G protein-coupled receptor, is remarkably expressed in osteoclast precursors, though it cannot be predominantly detected in the osteoblast lineage. Cell culture studies have confirmed that recombinant CXCL1 is able to stimulate the migration of osteoclast precursors in a dose-dependent manner [31]. Moreover, CXCL1 has been proven to promote osteoclast formation in vitro [32].

The superfamily of ADAM metallopeptidases with thrombospondin type 1 motifs (ADAMTSs) comprises 19 distinct ADAMTSs, which consist of secreted enzymes and seven ADAMTS-like proteins (ADAMTSLs) without enzymatic activity [33-35]. Most of them are involved in the generation and degradation of extracellular matrix (ECM) molecules, and participate in the formation and remodeling of connective tissue and the occurrence and development of diseases [34, 36]. The ECM of normal cartilage maintains a dynamic balance between generation and degradation, which is in a state of equilibrium. There is a loss of balance between proteases and their inhibitors that degrade the ECM in pathological cartilage. ADAMTS3 has been proven to be involved in the formation of type II fibrous collagen in articular cartilage [37]. ADAMTS16 has not yet been shown to have a specific function in articular cartilage. Current studies have shown that the expression of ADAMTS16 is increased in cartilage and synovium from osteoarthritis patients compared with normal controls $[38,39]$. The steady increase in the expression of ADAMTS16 will cause the inhibition of cell proliferation, migration, and adhesion, and a decrease in the expression of matrix metalloproteinase-13 (MMP13) in chondrosarcoma cells [40]. Studies have indicated that ADAMTSLs possess specific extracellular ligands and several of them are ECM-binding proteins that act at the cell-matrix interface [41-43]. It is well known that fibrillin microfibrils are able to bind to ADAMTSLs [44-47].
Therefore, ADAMTSLs can be regarded as matricellular proteins, which are non-structural proteins that express ECM dynamically and have regulatory effects.

PENK, a classically identified opioid gene, was initially shown to be expressed almost exclusively in the mature nervous and neuroendocrine systems. Current studies have revealed that the expression of PENK is selectively increased in mineralized cultures and is essential for the formation and remodeling of bone structure [48]. The expression of PENK in osteoblasts is regulated by bonetargeting hormones, which make a valuable contribution to bone development [49].

The interaction among bone formation and hub genes GPR18 and CALB2 has not yet been reported. GPR18 is a receptor for endocannabinoid $\mathrm{N}$-arachidonyl glycine (NAGly) [50, 51]. GPR18 may be involved in the regulation of the immune system, whose activity is mediated by $\mathrm{G}$ proteins that can inhibit adenylyl cyclase [50]. CALB2, a member of the troponin $C$ superfamily, is an intracellular calcium-binding protein that is abundant in auditory neurons and functions as a modulator of neuronal excitability.

\section{Conclusions}

In summary, the current study aims to determine potential biomarkers that might be related to the development of $\mathrm{HO}$ and to explore the potential mechanism of $\mathrm{HO}$. In total, 275 DEGs and 8 hub genes were identified, which provided a new promising perspective for $\mathrm{HO}$ diagnosis and treatment. The progression of $\mathrm{HO}$ may be prevented, alleviated, or even reversed by manipulating these candidate targets in the future. However, the detailed functions of these biomarkers in the pathogenesis of $\mathrm{HO}$ need to be studied further.

\section{Abbreviations}

HO: Heterotopic ossification; BMSCs: Bone marrow mesenchymal stem cells; GEO: Gene Expression Omnibus; DEGs: Differentially expressed genes; PPI: Protein-protein interaction; STRING: Search Tool for the Retrieval of Interacting Genes; GO: Gene Ontology; KEGG: Kyoto Encyclopaedia of Genes and Genomes; BP: Biological process; EFNB3: Ephrin B3; UNC5C: Unc-5 netrin

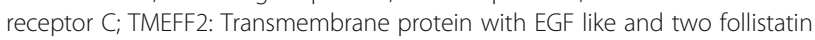
like domains 2; PTH2: Parathyroid hormone 2; KIT: Mast/stem cell growth factor receptor kit; FGF13: Fibroblast growth factor 13; WISP3: WNT1 inducible signaling pathway; MAP K10: Mitogen-activated protein kinase 10; DDIT3: DNA damage inducible transcript 3; COL4A4: Collagen type IV alpha 4 chain; DKK2: Dickkopf WNT signaling pathway inhibitor 2; MAPK: Mitogenactivated protein kinase; PI3K/Akt: Phosphatidylinositol-3-kinase/protein kinase $\mathrm{B} ; \mathrm{CX} 3 \mathrm{CL} 1$ : C-X3-C motif chemokine ligand 1; CXCL1: C-X-C motif chemokine ligand 1; ADAMTS: ADAM metallopeptidase with thrombospondin type 1 motif; ADAMTSLs: ADAMTS-like proteins; PENK: Proenkephalin; GPR18: G protein-coupled receptor 18;

CALB2: Calbindin 2; FOP: Progressive ossifying fibrous dysplasia; PCA: Principal components analysis; DAVID: Database for Annotation, Visualization and Integrated Discovery; MCODE: Molecular Complex Detection; CX3CR1: CX3C receptor 1; CXCR2: CXC receptor 2; RANKL/ OPG: Receptor activator of nuclear factor-kappa B ligand/osteoprotegerin; ECM: Extracellular matrix; MMP13: Matrix metalloproteinase 13; NAGly: Narachidonyl glycine 


\section{Acknowledgements}

Not applicable.

\section{Authors' contributions}

YZY and SB conceived and designed the study. YZY, LDL, and LX analyzed the data and wrote the manuscript. The original text was drafted and modified by GR and WYW. All authors read and approved the final manuscript.

\section{Funding}

This research did not receive any specific grant from funding agencies in the public, commercial, or not-for-profit sectors.

\section{Availability of data and materials}

All data generated or analyzed during this study are included in published articles.

\section{Declarations}

\section{Ethics approval and consent to participate}

This article does not contain any studies with human participants or animals performed by any of the authors.

\section{Consent for publication}

Not applicable.

\section{Competing interests}

All authors declare they have no competing interests.

Received: 28 May 2021 Accepted: 7 August 2021

Published online: 14 August 2021

\section{References}

1. Hoch B, Montag A. Reactive bone lesions mimicking neoplasms. Semin Diagn Pathol. 2011;28(1):102-12. https://doi.org/10.1053/j.semdp.2011.02 011.

2. Mavrogenis AF, Soucacos PN, Papagelopoulos PJ. Heterotopic ossification revisited. Orthopedics. 2011;34(3):177. https://doi.org/10.3928/01477447-2 0110124-08.

3. Meyers C, Lisiecki J, Miller S, Levin A, Fayad L, Ding C, et al. Heterotopic Ossification: A Comprehensive Review. JBMR Plus. 2019;3(4):e10172. https:// doi.org/10.1002/jbm4.10172.

4. van Dinther M, Visser N, de Gorter DJ, Doorn J, Goumans MJ, de Boer J, et al. ALK2 R206H mutation linked to fibrodysplasia ossificans progressiva confers constitutive activity to the BMP type I receptor and sensitizes mesenchymal cells to BMP-induced osteoblast differentiation and bone formation. J Bone Miner Res. 2010;25(6):1208-15.

5. Shore EM, Xu M, Feldman GJ, Fenstermacher DA, Cho TJ, Choi IH, et al. A recurrent mutation in the BMP type I receptor ACVR1 causes inherited and sporadic fibrodysplasia ossificans progressiva. Nat Genet. 2006;38(5):525-7. https://doi.org/10.1038/ng1783.

6. Fukuda T, Kohda M, Kanomata K, Nojima J, Nakamura A, Kamizono J, et al. Constitutively activated ALK2 and increased SMAD $1 / 5$ cooperatively induce bone morphogenetic protein signaling in fibrodysplasia ossificans progressiva. J Biol Chem. 2009;284(11):7149-56. https://doi.org/10.1074/jbc M801681200.

7. Chakkalakal SA, Zhang D, Culbert AL, Convente MR, Caron RJ, Wright AC, et al. An Acvr1 R206H knock-in mouse has fibrodysplasia ossificans progressiva. J Bone Miner Res. 2012;27(8):1746-56. https://doi.org/10.1002/ jbmr.1637.

8. Sakellariou VI, Grigoriou E, Mavrogenis AF, Soucacos PN, Papagelopoulos PJ. Heterotopic ossification following traumatic brain injury and spinal cord injury: insight into the etiology and pathophysiology. J Musculoskelet Neuronal Interact. 2012;12(4):230-40.

9. Seipel R, Langner S, Platz T, Lippa M, Kuehn JP, Hosten N. Neurogenic heterotopic ossification: epidemiology and morphology on conventional radiographs in an early neurological rehabilitation population. Skelet Radiol. 2012;41(1):61-6. https://doi.org/10.1007/s00256-011-1115-5.

10. Genet F, Chehensse C, Jourdan C, Lautridou C, Denormandie P, Schnitzler A. Impact of the operative delay and the degree of neurologic sequelae on recurrence of excised heterotopic ossification in patients with traumatic brain injury. J Head Trauma Rehabil. 2012;27(6):443-8. https://doi.org/10.1 097/HTR.0b013e31822b54ba.

11. Xu JC, Wu GH, Zhou LL, Yang XJ, Liu JT. Establishment of heterotopic ossification via sharp instrument injury in rats. J Musculoskelet Neuronal Interact. 2017;17(1):456-60.

12. Brady RD, Shultz SR, McDonald SJ, O'Brien TJ. Neurological heterotopic ossification: Current understanding and future directions. Bone. 2018;109: 35-42. https://doi.org/10.1016/j.bone.2017.05.015.

13. Mediouni M, Schlatterer DR, Madry H, Cucchiarini M, Rai B. A review of translational medicine. The future paradigm: how can we connect the orthopedic dots better? Curr Med Res Opin. 2018;34(7):1217-29. https://doi. org/10.1080/03007995.2017.1385450.

14. Mediouni M. A new generation of orthopaedic surgeons: "T-model". Curr Orthop Prac. 2019;30(5):444-5. https://doi.org/10.1097/BCO. 0000000000000786.

15. Torossian F, Guerton B, Anginot A, Alexander KA, Desterke C, Soave S, et al. Macrophage-derived oncostatin $M$ contributes to human and mouse neurogenic heterotopic ossifications. JCl Insight. 2017;2(21).

16. Kanehisa M, Goto S. KEGG: kyoto encyclopedia of genes and genomes. Nucleic Acids Res. 2000;28(1):27-30. https://doi.org/10.1093/nar/28.1.27.

17. Gene Ontology Consortium. The Gene Ontology (GO) project in 2006. Nucleic Acids Res. 2006;34(Database issue):D322-6.

18. Dennis G Jr, Sherman BT, Hosack DA, Yang J, Gao W, Lane HC, et al. DAVID: Database for Annotation, Visualization, and Integrated Discovery. Genome Biol. 2003;4(5):P3. https://doi.org/10.1186/gb-2003-4-9-r60.

19. Szklarczyk D, Franceschini A, Wyder S, Forslund K, Heller D, Huerta-Cepas J, et al. STRING v10: protein-protein interaction networks, integrated over the tree of life. Nucleic Acids Res. 2015;43(Database issue):D447-52. https://doi. org/10.1093/nar/gku1003.

20. Agarwal S, Loder S, Brownley C, Cholok D, Mangiavini L, Li J, et al. Inhibition of Hif1 alpha prevents both trauma-induced and genetic heterotopic ossification. Proc Natl Acad Sci U S A. 2016;113(3):E338-47. https://doi.org/1 $0.1073 /$ pnas. 1515397113 .

21. Choi YH, Kim KE, Lim SH, Lim JY. Early presentation of heterotopic ossification mimicking pyomyositis - two case reports. Ann Rehabil Med. 2012;36(5):713-8. https://doi.org/10.5535/arm.2012.36.5.713.

22. Molligan J, Mitchell R, Schon L, Achilefu S, Zahoor T, Cho Y, et al. Influence of bone and muscle injuries on the osteogenic potential of muscle progenitors: contribution of tissue environment to heterotopic ossification. Stem Cells Transl Med. 2016;5(6):745-53. https://doi.org/10.5966/sctm.2015-0082.

23. Niedzwiedzki T, Filipowska J. Bone remodeling in the context of cellular and systemic regulation: the role of osteocytes and the nervous system. J Mol Endocrinol. 2015;55(2):R23-36. https://doi.org/10.1530/JME-15-0067.

24. Brylka $\sqcup$, Schinke T. Chemokines in physiological and pathological bone remodeling. Front Immunol. 2019;10:2182. https://doi.org/10.3389/fimmu.2 019.02182.

25. Koizumi K, Saitoh Y, Minami T, Takeno N, Tsuneyama K, Miyahara T, et al. Role of CX3CL1/fractalkine in osteoclast differentiation and bone resorption. J Immunol. 2009;183(12):7825-31.

26. Isozaki T, Kasama T, Takahashi R, Odai T, Wakabayashi K, Kanemitsu H, et al. Synergistic induction of CX3CL1 by TNF alpha and IFN gamma in osteoblasts from rheumatoid arthritis: involvement of NF-kappa B and STAT1 signaling pathways. J Inflamm Res. 2008;1:19-28. https://doi.org/10.2147/ jir.s4019.

27. Matsuura T, Ichinose S, Akiyama M, Kasahara Y, Tachikawa N, Nakahama KI. Involvement of CX3CL1 in the migration of osteoclast precursors across osteoblast layer stimulated by interleukin-1ss. J Cell Physiol. 2017;232(7): 1739-45. https://doi.org/10.1002/jcp.25577.

28. Ibanez L, Abou-Ezzi G, Ciucci T, Amiot V, Belaid N, Obino D, et al. Inflammatory osteoclasts prime TNFalpha-producing CD4(+) T cells and express CX3 CR1. J Bone Miner Res. 2016;31(10):1899-908. https://doi.org/1 $0.1002 / j b m r .2868$.

29. Hoshino A, Ueha S, Hanada S, Imai T, Ito M, Yamamoto K, et al. Roles of chemokine receptor CX3CR1 in maintaining murine bone homeostasis through the regulation of both osteoblasts and osteoclasts. J Cell Sci. 2013; 126(Pt 4):1032-45. https://doi.org/10.1242/jcs.113910.

30. Lee YC, Gajdosik MS, Josic D, Clifton JG, Logothetis C, Yu-Lee LY, et al. Secretome analysis of an osteogenic prostate tumor identifies complex signaling networks mediating cross-talk of cancer and stromal cells within the tumor microenvironment. Mol Cell Proteomics. 2015;14(3):471-83. https://doi.org/10.1074/mcp.M114.039909. 
31. Onan D, Allan EH, Quinn JM, Gooi JH, Pompolo S, Sims NA, et al. The chemokine $\mathrm{Cxcl} 1$ is a novel target gene of parathyroid hormone (PTH)/PTHrelated protein in committed osteoblasts. Endocrinology. 2009;150(5):224453. https://doi.org/10.1210/en.2008-1597.

32. Hardaway AL, Herroon MK, Rajagurubandara E, Podgorski I. Marrow adipocyte-derived CXCL1 and CXCL2 contribute to osteolysis in metastatic prostate cancer. Clin Exp Metastasis. 2015;32(4):353-68. https://doi.org/10.1 007/s10585-015-9714-5.

33. Kuno K, Kanada N, Nakashima E, Fujiki F, Ichimura F, Matsushima K. Molecular cloning of a gene encoding a new type of metalloproteinasedisintegrin family protein with thrombospondin motifs as an inflammation associated gene. J Biol Chem. 1997;272(1):556-62. https://doi.org/10.1074/ jbc.272.1.556.

34. Apte SS. A disintegrin-like and metalloprotease (reprolysin-type) with thrombospondin type 1 motif (ADAMTS) superfamily: functions and mechanisms. J Biol Chem. 2009;284(46):31493-7. https://doi.org/10.1074/jbc. R109.052340.

35. Apte SS. A disintegrin-like and metalloprotease (reprolysin type) with thrombospondin type 1 motifs: the ADAMTS family. Int J Biochem Cell Biol. 2004;36(6):981-5. https://doi.org/10.1016/j.biocel.2004.01.014.

36. Dubail J, Apte SS. Insights on ADAMTS proteases and ADAMTS-like proteins from mammalian genetics. Matrix Biol. 2015;44-46:24-37.

37. Fernandes RJ, Hirohata S, Engle JM, Colige A, Cohn DH, Eyre DR, et al. Procollagen II amino propeptide processing by ADAMTS-3. Insights on dermatosparaxis. J Biol Chem. 2001;276(34):31502-9. https://doi.org/10.1074/ jbc.M103466200.

38. Kevorkian L, Young DA, Darrah C, Donell ST, Shepstone L, Porter S, et al. Expression profiling of metalloproteinases and their inhibitors in cartilage. Arthritis Rheum. 2004;50(1):131-41. https://doi.org/10.1002/art.11433.

39. Davidson RK, Waters JG, Kevorkian L, Darrah C, Cooper A, Donell ST, et al. Expression profiling of metalloproteinases and their inhibitors in synovium and cartilage. Arthritis Res Ther. 2006;8(4):R124. https://doi.org/10.1186/ar2 013.

40. Surridge AK, Rodgers UR, Swingler TE, Davidson RK, Kevorkian L, Norton R, et al. Characterization and regulation of ADAMTS-16. Matrix Biol. 2009;28(7): 416-24. https://doi.org/10.1016/j.matbio.2009.07.001.

41. Hirohata S, Wang LW, Miyagi M, Yan L, Seldin MF, Keene DR, et al. Punctin, a novel ADAMTS-like molecule, ADAMTSL-1, in extracellular matrix. J Biol Chem. 2002;277(14):12182-9. https://doi.org/10.1074/jbc.M109665200.

42. Hall NG, Klenotic P, Anand-Apte B, Apte SS. ADAMTSL-3/punctin-2, a novel glycoprotein in extracellular matrix related to the ADAMTS family of metalloproteases. Matrix Biol. 2003;22(6):501-10. https://doi.org/10.1016/ S0945-053X(03)00075-1.

43. Koo BH, Le Goff C, Jungers KA, Vasanji A, O'Flaherty J, Weyman CM, et al. ADAMTS-like 2 (ADAMTSL2) is a secreted glycoprotein that is widely expressed during mouse embryogenesis and is regulated during skeletal myogenesis. Matrix Biol. 2007;26(6):431-41. https://doi.org/10.1016/j.ma tbio.2007.03.003.

44. Le Goff C, Mahaut C, Wang LW, Allali S, Abhyankar A, Jensen S, et al. Mutations in the TGFbeta binding-protein-like domain 5 of FBN1 are responsible for acromicric and geleophysic dysplasias. Am J Hum Genet 2011;89(1):7-14. https://doi.org/10.1016/j.ajhg.2011.05.012.

45. Gabriel LA, Wang LW, Bader H, Ho JC, Majors AK, Hollyfield JG, et al. ADAMTSL4, a secreted glycoprotein widely distributed in the eye, binds fibrillin-1 microfibrils and accelerates microfibril biogenesis. Invest Ophthalmol Vis Sci. 2012;53(1):461-9. https://doi.org/10.1167/iovs.10-5955.

46. Bader HL, Wang LW, Ho JC, Tran T, Holden P, Fitzgerald J, et al. A disintegrin-like and metalloprotease domain containing thrombospondin type 1 motif-like 5 (ADAMTSL5) is a novel fibrillin-1-, fibrillin-2-, and heparinbinding member of the ADAMTS superfamily containing a netrin-like module. Matrix Biol. 2012;31(7-8):398-411. https://doi.org/10.1016/j.matbio.2 012.09.003.

47. Tsutsui K, Manabe R, Yamada T, Nakano I, Oguri Y, Keene DR, et al. ADAMTSL-6 is a novel extracellular matrix protein that binds to fibrillin-1 and promotes fibrillin-1 fibril formation. J Biol Chem. 2010;285(7):4870-82. https://doi.org/10.1074/jbc.M109.076919.

48. Seitz S, Barvencik F, Gebauer M, Albers J, Schulze J, Streichert T, et al. Preproenkephalin (Penk) is expressed in differentiated osteoblasts, and its deletion in Hyp mice partially rescues their bone mineralization defect. Calcif Tissue Int. 2010;86(4):282-93. https://doi.org/10.1007/s00223-010-9344-5.
49. Rosen H, Krichevsky A, Polakiewicz RD, Benzakine S, Bar-Shavit Z. Developmental regulation of proenkephalin gene expression in osteoblasts. Mol Endocrinol. 1995;9(11):1621-31.

50. Kohno M, Hasegawa H, Inoue A, Muraoka M, Miyazaki T, Oka K, et al. Identification of $\mathrm{N}$-arachidonylglycine as the endogenous ligand for orphan G-protein-coupled receptor GPR18. Biochem Biophys Res Commun. 2006; 347(3):827-32. https://doi.org/10.1016/j.bbrc.2006.06.175.

51. Flegel C, Vogel F, Hofreuter A, Wojcik S, Schoeder C, Kiec-Kononowicz K, et al. Characterization of non-olfactory GPCRs in human sperm with a focus on GPR18. Sci Rep. 2016;6(1):32255. https://doi.org/10.1038/srep32255.

\section{Publisher's Note}

Springer Nature remains neutral with regard to jurisdictional claims in published maps and institutional affiliations.
Ready to submit your research? Choose BMC and benefit from:

- fast, convenient online submission

- thorough peer review by experienced researchers in your field

- rapid publication on acceptance

- support for research data, including large and complex data types

- gold Open Access which fosters wider collaboration and increased citations

- maximum visibility for your research: over $100 \mathrm{M}$ website views per year

At $\mathrm{BMC}$, research is always in progress.

Learn more biomedcentral.com/submissions 